\title{
COMPARAÇÃO DE QUATRO TIPOS DE BANDEJAS VISANDO A PRODUÇÃO DE MUDAS DE ALFACE
}

Juliana Andréa Osorio Balan ${ }^{1}$, Sérgio Minoru Oikawa ${ }^{1}$, Gabriela Coimbra Vernilo ${ }^{2}$, Valter Alves Pradela $^{2}$

${ }^{1}$ Universidade Estadual Paulista - UNESP, Curso de Estatística, Presidente Prudente, SP. ${ }^{2}$ Faculdade de Tecnologia FATEC, Curso de Agronegócio. Presidente Prudente, SP. E-mail: julianaosorio @hotmail.com

\section{RESUMO}

A alface predominante no Brasil é do tipo crespa, liderando $70 \%$ do mercado. Um dos grandes avanços no cultivo das hortaliças foi a produção de mudas individualizadas, utilizando bandejas celulares preenchidas com substrato. $O$ objetivo deste trabalho foi avaliar se houve diferenciação na obtenção das mudas de alface, partindo da formação das mudas em quatro tipos de bandejas descartável e isopor, sendo que cada bandeja possui um tamanho diferente de célula. 0 experimento foi delineado no esquema fatorial, utilizando o software R. Conclui-se que o uso das bandejas do tipo isopor e descartável contribuem igualmente para o crescimento da parte aérea das mudas de alface, independente do tamanho das células das bandejas. Os dois tipos de bandejas e os dois tamanhos das células apresentaram interação significativa, contribuindo conjuntamente para o crescimento da raiz das mudas de alface.

Palavras-chave: Lactuca sativa, substratos, olerícolas.

\section{COMPARISON OF FOUR TYPES OF PANS AIMING LETTUCE SEEDLINGS PRODUCTION}

\begin{abstract}
The predominant lettuce in Brazil is the curly type, leading with $70 \%$ market share. One of the great advances in the cultivation of vegetables was the production of individual seedlings using cell trays filled with substrate. The objective of this study was to evaluate if there was differentiation in obtaining the lettuce seedlings, starting from the formation of seedlings in four types of disposable Styrofoam trays, each tray has a different size cell. The experiment was conducted in factorial scheme, using the software R. We conclude that the use of styrofoam trays and disposable type also contribute the shoot growth of lettuce seedlings independ on the size of the cells of the trays. The two types of trays and the two sizes of the cells showed a significant interaction, thus jointly contributed to the root growth of lettuce seedlings.
\end{abstract}

Keywords: Lactuca sativa, substrates, vegetable crops. 


\section{INTRODUÇÃO}

A alface (Lactuca sativa L.) é a hortaliça folhosa de maior importância no Brasil (COSTA \& SALA, 2005), e constitui-se numa cultura de grande importância social na agricultura familiar e na alimentação humana. Esta espécie normalmente é plantada próximo aos centros consumidores, onde se procura cultivá-la o ano inteiro (FERREIRA et al., 2008). A alface predominante no Brasil é do tipo crespa, correspondendo a $70 \%$ do mercado. A alface do tipo americana detém $15 \%$, a lisa 10\%, enquanto outras (vermelha, mimosa, etc.) correspondem a 5\% do mercado (COSTA \& SALA, 2005). O grupo da alface tipo crespa vem crescendo consideravelmente nos últimos anos, em virtude de apresentar melhor resistência a doenças e ao transporte, maior período pós-colheita e melhor paladar, vantagens para o mercado consumidor da cadeia produtiva. $\mathrm{O}$ cultivo da alface crespa é preferido também pelos produtores, pois a hortaliça apresenta aspecto de manuseio e transporte facilitado devido à disposição de suas folhas, o que a torna preferível (RODRIGUES et al., 2007).

Tradicionalmente, a alface é adaptada a condições de temperaturas amenas, com maior produção nas épocas mais frias do ano (MOMENTÉ et al., 2007). Diversos materiais podem ser utilizados como substratos hortícolas, sendo divididos em duas grandes categorias: minerais ; como por exemplo, a areia, vermiculita e a lã de rocha e orgânicos; como por exemplo a turfa, casca de arroz, casca de café, palha e serragens. Os substratos de origem mineral apresentam como maior vantagem sua inércia química. Os de origem orgânica podem sofrer alguma decomposição durante o período em que estão em contato com as raízes das plantas. Essa decomposição, se for intensa, pode modificar o equilíbrio mineral do meio radicular (ANDRIOLO, 1999 b).

As quantidades de macro e micronutrientes presentes no substrato devem estar em níveis adequados, que favoreçam a implantação da cultura desejada. Os materiais empregados devem apresentar em sua estrutura física a capacidade de reter água em potencial matricial baixo para que a cultura não utilize grande quantidade de energia para absorvê-la. Dessa forma, os elementos orgânicos que apresentam essas características, são recomendados para uso como substrato agrícola (KOYANAGUI et. al., 2008). A função do substrato é de dar suporte à cultura, fornecendo água, nutrientes e oxigênio. Para que ocorra a utilização pelo produtor, os materiais devem oferecer custos mais acessíveis, ampla disponibilidade local, pH próximo a 6, boa fertilidade e a capacidade de Troca Catiônica. Os materiais deverão estar isentos de pragas, fitopatógenos e elementos tóxicos, além de conter atributos físicos que proporcione aeração e retenção de água em níveis que atendam a demanda da cultura (KOYANAGUI et. al., 2008). Para 
Maciel (2007), a eficiência do substrato está diretamente relacionada a uma boa formação das mudas destinadas a produção vegetal. Um bom substrato deve ter uma boa capacidade de aeração, drenagem, retenção de água e disponibilidade balanceada de nutrientes. A formação do sistema radicular e a parte aérea estão associadas com essas características, sendo que as duas primeiras características estão relacionadas com a microporosidade e superfície específica do substrato.

O grande avanço no cultivo das hortaliças foi à produção de mudas individualizadas, utilizando bandejas celulares preenchidas com substrato. Esta técnica facilitou o manuseio, maior controle nutricional e fitossanitário nas mudas (FURLAN et al., 2007), garantindo qualidade e baixo custo. O método recomendado quando se pretende estabelecer um cultivo comercial, assegurando melhor desenvolvimento e eliminando falhas no campo. É normalmente feito em bandejas de plástico ou isopor (poliestireno expandido), com diferentes dimensões das células: 288 células ( $47 \times 22 \mathrm{~mm}$ - profundidade x largura da célula) e 200 (48 × $26 \mathrm{~mm}$ ), entre outras as mais comumente utilizadas.

O objetivo deste trabalho foi avaliar junto à empresa Mudas Ribeiro ${ }^{\circledR}$, localizada no município de Alfredo Marcondes, se houve diferença na obtenção de mudas de alface crespa (variedade Solaris) em função da utilização de bandejas do tipo descartável e isopor com dois tamanhos de célula.

\section{MATERIAL E MÉTODOS}

O experimento foi conduzido no viveiro de mudas da empresa Mudas Ribeiro ${ }^{\circledR}$, localizada no município de Alfredo Marcondes. O experimento foi delineado no sistema fatorial 2x2, sendo a análise de variância (ANOVA) e comparações entre médias realizadas pelo sistema de Delineamento Inteiramente Casualizado (DIC), utilizando o software R-project. Todas as bandejas foram semeadas no mesmo dia, e postas em um viveiro de mudas, sendo submetidas às mesmas doses de fertilizantes e quantidade de água pela irrigação mecanizada. Foi feito um acompanhamento semanal desde a germinação até o porte de transplante. As avaliações se realizaram aos 25 dias após a semeadura, quando as mudas já estavam em ponto para serem transplantadas para o solo. Para a realização das avaliações, foram selecionadas 2 fileiras (10 mudas cada fileira) ao acaso de cada bandeja, com 4 repetições e descartando a bordadura. Foram avaliados a massa fresca da parte aérea e a massa fresca das raízes. A pesagem foi feita com o uso de balança de precisão. 


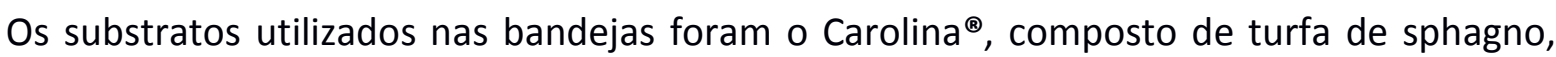
vermiculita expandida, casca de arroz carbonizada, calcário dolomítico, gesso agrícola e

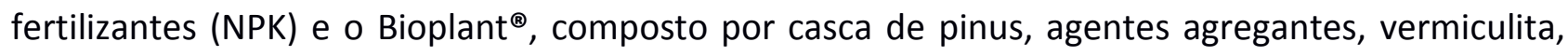
fibra de coco e complementos minerais (NPK + MICRO).

\section{RESULTADOS}

A análise de variância da massa fresca da parte aérea das mudas de alface (Tabela 1) mostrou que as bandejas do tipo isopor e descartável influenciaram no crescimento da parte aérea das mudas de alface (Fator A). O tamanho das células não influenciou este crescimento (Fator B). Não houve interação significativa entre os fatores (Fator AxB).

Tabela 1. Análise de variância da massa fresca, em gramas, da parte aérea de mudas de alface para bandejas, tamanho das células das bandejas e a interação.

\begin{tabular}{cccccc}
\hline $\begin{array}{c}\text { Causa de } \\
\text { Variação }\end{array}$ & $\begin{array}{c}\text { Graus de } \\
\text { Liberdade }\end{array}$ & $\begin{array}{c}\text { Soma de } \\
\text { Quadrados }\end{array}$ & $\begin{array}{c}\text { Quadrado } \\
\text { Médio }\end{array}$ & $\mathrm{F}_{0}$ & P-valor \\
\hline Fator A & 1 & 14,062 & 14,062 & 9,783 & $0,00873^{* *}$ \\
\hline Fator B & 1 & 0,063 & 0,063 & 0,043 & 0,83832 \\
\hline Fator AxB & 1 & 1,563 & 1,563 & 1,087 & 0,31770 \\
\hline Resíduos & 12 & 17,250 & 1,438 & & \\
\hline
\end{tabular}

** Significativo ao teste $\mathrm{F}$ ao nível de $5 \%$ de probabilidade.

O teste de Tukey para comparação das médias dos fatores (Tabela 2) mostra que não houve diferença significativa entre os fatores, assim as bandejas do tipo isopor e descartável contribuem igualmente para o crescimento da parte aérea das mudas de alface.

Tabela 2. Teste de Tukey para comparação das médias dos fatores, utilizando intervalo de confiança.

\begin{tabular}{cccc}
\hline Fatores & Diferença & Limite inferior & Limite superior \\
\hline B-A & -1.875 & -3.181152 & -0.5688476 \\
\hline
\end{tabular}

Não significativo ao teste Tukey ao nível de $5 \%$ de probabilidade.

A análise de variância do peso verde da raiz das mudas de alface (Tabela 3) apresentou interação significativa entre os tipos de bandejas e o tamanho das células (Fator AxB). Isto significou que os fatores e níveis contribuíram para o crescimento da massa fresca da raiz das mudas de alface. 
Tabela 3. Análise de variância da massa fresca da raiz de mudas de alface (em gramas) para bandejas, tamanho das células das bandejas e a interação.

\begin{tabular}{cccccc}
\hline $\begin{array}{c}\text { Causa de } \\
\text { Variação }\end{array}$ & $\begin{array}{c}\text { Graus de } \\
\text { Liberdade }\end{array}$ & $\begin{array}{c}\text { Soma de } \\
\text { Quadrados }\end{array}$ & $\begin{array}{c}\text { Quadrado } \\
\text { Médio }\end{array}$ & $\mathrm{F}_{0}$ & P-valor \\
\hline Fator A & 1 & 9950 & 9950 & 458,79 & $6,25 \mathrm{e}-11^{* * *}$ \\
\hline Fator B & 1 & 9851 & 9851 & 545,20 & $6,63 \mathrm{e}-11^{* * *}$ \\
\hline Fator AxB & 1 & 203 & 260 & 9,36 & $0,0099^{* *}$ \\
\hline Resíduos & 12 & 260 & 22 & & \\
\hline
\end{tabular}

**Significativos ao teste $\mathrm{F}$ ao nível de $5 \%$ de probabilidade.

Fonte dos autores.

O delineamento experimental no esquema fatorial permitiu identificar se houve dependência dos níveis dentro dos fatores (A), dos fatores dentro dos níveis (B) ou em ambos os casos. Assim, o estudo da interação (Tabelas 4 e 5) foi significativo para a interação dos níveis dentro dos fatores e dos fatores dentro dos níveis.

Tabela 4. Análise de variância da interação dos fatores dentro dos níveis.

\begin{tabular}{|c|c|c|c|c|c|}
\hline $\begin{array}{l}\text { Causa de } \\
\text { Variação }\end{array}$ & $\begin{array}{l}\text { Graus de } \\
\text { Liberdade }\end{array}$ & $\begin{array}{c}\text { Soma de } \\
\text { Quadrados }\end{array}$ & $\begin{array}{l}\text { Quadrado } \\
\text { Médio }\end{array}$ & $\mathrm{F}_{0}$ & P-valor \\
\hline Fator A & 1 & 9950 & 9950 & 458,79 & $6,25 \mathrm{e}-11 * * *$ \\
\hline $\begin{array}{c}\text { Fator A dentro } \\
\text { do Fator B }\end{array}$ & 2 & 10053 & 5026,5 & 231,78 & $6,58 \mathrm{e}-11^{* * *}$ \\
\hline Resíduos & 12 & 260 & 22 & & \\
\hline
\end{tabular}

Tabela 5. Análise de variância da interação dos níveis dentro dos fatores.

\begin{tabular}{cccccc}
\hline $\begin{array}{c}\text { Causa de } \\
\text { Variação }\end{array}$ & $\begin{array}{c}\text { Graus de } \\
\text { Liberdade }\end{array}$ & $\begin{array}{c}\text { Soma de } \\
\text { Quadrados }\end{array}$ & $\begin{array}{c}\text { Quadrado } \\
\text { Médio }\end{array}$ & $\mathrm{F}_{0}$ & P-valor \\
\hline Fator B & 1 & 9851 & 9851 & 454,20 & $6,63 \mathrm{e}-11^{* * *}$ \\
\hline $\begin{array}{c}\text { Fator B dentro } \\
\text { do Fator A }\end{array}$ & 2 & 10153 & 5076,5 & 234,08 & $2,43 \mathrm{e}-11^{* * *}$ \\
\hline Resíduos & 12 & 260 & 22 & & \\
\hline
\end{tabular}

***Significativos ao teste $\mathrm{F}$ ao nível de $5 \%$ de probabilidade.

Fonte dos autores

O teste de Tukey (Tabela 6) apresentou diferença significativa entre as bandejas do tipo isopor para os dois tamanhos de células, entre as bandejas do tipo descartável para os dois tamanhos de células e a bandeja do tipo descartável de 200 células com os dois tamanhos de bandejas de isopor. 
Tabela 6. Teste de Tukey para comparação das médias dos fatores e níveis, utilizando intervalo de confiança.

\begin{tabular}{cccc}
\hline Fatores & Diferença & Limite inferior & Limite superior \\
\hline $288(I)-200(I)$ & 42,50 & 32,72345 & $52,276547^{*}$ \\
\hline $200(D)-200(I)$ & $-57,00$ & $-66,77655$ & $-47,223453^{*}$ \\
\hline $288(D)-200(I)$ & $-0,25$ & $-10,02655$ & 9,526547 \\
\hline $200(D)-288(I)$ & $-99,50$ & $-109,27655$ & $-89,723453^{*}$ \\
\hline $288(D)-288(I)$ & $-42,75$ & $-52,52655$ & 32,973453 \\
\hline $288(D)-200(D)$ & 56,75 & 46,97345 & $66,526547^{*}$ \\
\hline
\end{tabular}

*Significativo ao teste Tukey ao nível de $5 \%$ de probabilidade

Fonte dos autores.

\section{DISCUSSÃO}

No presente trabalho conclui-se que o uso das bandejas do tipo isopor e descartável contribuem igualmente para o crescimento da parte aérea das mudas de alface. Trani et al. (2004), observaram que nas bandejas do tipo descartável com 200 células, em função do maior volume de substrato, as plantas apresentaram área foliar maior que nas de 288 células. Ainda Trani et al. (2004) verificaram que em ambos os tipos de bandejas descartáveis (200 e 288 células) houve a mesma estabilidade da raiz aos 15 e aos 20 dias. Porém, aos 25 dias houve diferença significativa para o crescimento da raiz comparando-se a bandeja do tipo isopor (200 e 288 células) e a bandeja do tipo descartável com 200 células.

Farinacio et al. (2010) relatou que o tipo de substrato utilizado e a bandeja exercem grande influência no desenvolvimento da cultura da alface, tanto na produção de mudas como no seu rendimento final e verificou, do ponto de vista das qualidades das mudas, que a bandeja com 200 células apresentou um desenvolvimento intermediário e as de 288 células apresentou um menor desenvolvimento.

\section{CONCLUSÃO}

Conclui-se que o uso das bandejas do tipo isopor e descartável contribuem igualmente o crescimento da parte aérea das mudas de alface.

A utilização de bandeja de isopor com 200 e 288 células e bandeja descartável com 200 células resultou em diferença significativa para o crescimento da raiz das mudas de alface. 


\section{REFERÊNCIAS}

ANDRIOLO, J.L. Fisiologia das culturas protegidas. Santa Maria: Ed. da UFSM, 1999 (b). 142 p.

COSTA, C.P; SALA, F.C. A evolução da alfacicultura brasileira. Horticultura Brasileira, 23:820-824, 2005.

FARINACIO, D.; GODOY, W.I.; CARNEIRO, S.A.P.; WURTZIUS, V.; FUNGUETTO, R. F. Desenvolvimento inicial e produção de alface a partir de diferentes substratos e bandejas. In: VII ENSub, Goiânia-GO, 2010.

FERREIRA, S.; SANTOS, D.C.; GOMES, L.A.A.; MALUF, W.R. Amplitude de variação quanto ao número de dias para florescimento em diferentes genótipos de alface. In: Congresso Brasileiro de Olericultura, 48. Maringá: ABH, 2008. (CD-ROM).

FURLAN, F.; COSTA, M. S. S. M.; COSTA, L. A. M.; MARINI, D.; CASTOLDI, G.; SOUZA, J. H.; PIVETTA, L. A.; PIVETTA, L. G. Substratos alternativos para produção de mudas de couve folha em sistema orgânico. Revista Brasileira de Agroecologia, Porto Alegre-RS, v. 2, n. 2, p. 1686-1689, 2007.

KOYANAGUI, M. T.; SILVA, E. A.; OLIVEIRA, A. C.; MARUYAMA, W. I.; REZENDE, W. E.; BARBOSA, M. M. M. Diferentes substratos na germinação de sementes e produção de mudas de romãzeira (Punica granatum I.). In: Congresso Brasileiro de Fruticultura, 20. Annual Meeting of the Interamerian Society for Tropical Horticulture, 45. Vitória-ES. Jaboticabal-SP: Sociedade Brasileira de Fruticultura, 2008.

MACIEL, P. H. F. Z. A.; Rocha, D. S.; PARO, P.; GIODA, M.; BOTREL, M. C. G. Produção de mudas de Jatropha curcas L. em diferentes substratos. In: Congresso da Academia Trinacional de Ciências, 2. Mostra de Trabalhos e Protótipos, 2. Workshop do PDTA - Programa de Desenvolvimento Tecnológico Avançado, 2. Foz do Iguaçu - PR. Resumos Foz do Iguaçu-PR: 25 Universidade Estadual do Oeste do Paraná (UNIOESTE), 2007.

MOMENTÉ, V.G.; BARRETO, H.G.; SILVEIRA, M.A.; SANTANA, W.R.; TAVARES, I.B.; SOUZA, R.C.; ANDRE, C.M.G. Avaliação de linhagens $\mathbf{F 8}$ de alface ao pendoamento precoce sob condições de temperaturas elevadas de Palmas-TO. In: Congresso Brasileiro de Olericultura, 47. Resumos. Porto Seguro: ABH, 2007. (CD-ROM).

RODRIGUES, I.N.; LOPES, M.T.G.; LOPES, R.; GAMA, A.S.; MILAGRES, C.P. Avaliação de cultivares de alface crespa para a região de Manaus. In: Congresso Brasileiro de Olericultura, 47. Resumos. Porto Seguro: $A B H$, 2007. (CD ROM).

TRANI, P.E.; NOVO, M.C.S.S.; CAVALLARO J/NIOR, M.L.; TELLES, L.M.G. Produção de mudas de alface em bandejas e substratos comerciais. Horticultura Brasileira, Brasilia, v.22, n.2, p.290-294, abril-junho 2004. http://dx.doi.org/10.1590/S0102-05362004000200025 